Mean duration in days per

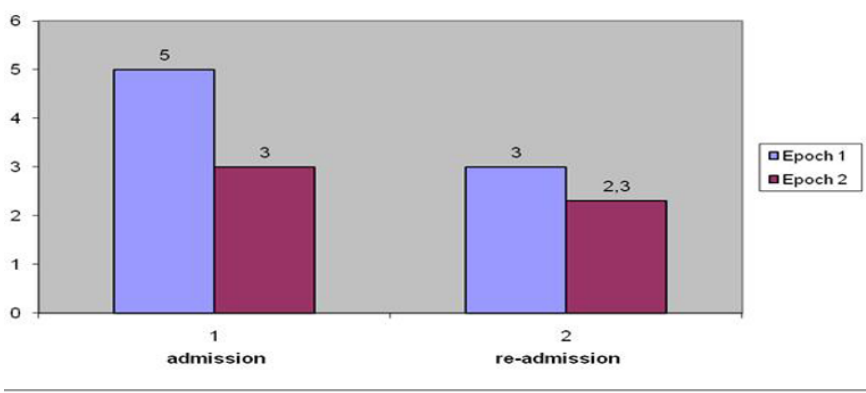

Mean cost (£300/day) per

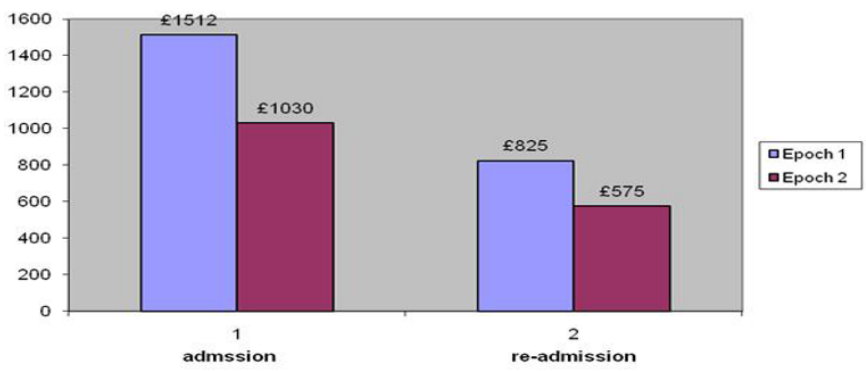

[Figure $1 \&$ 2]

757

\section{EARLY HIGH-FREQUENCY OSCILLATORY VENTILATION VERSUS SYNCHRONIZED INTERMITTENT MANDATORY VENTILATION IN VERY LOW BIRTH WEIGHT INFANTS WITH VISCEROABDOMINAL DISPROPORTION}

\author{
O. Nazarchuk, D. Dmytriiev, K. Dmytriieva,
} O. Katilov

\section{Vinnitsa National Medical University, Vinnitsa, Ukraine}

Objective: This is trial comparing early highfrequency oscillatory ventilation (HFOV) to synchronized intermittent mandatory ventilation (SIMV) in very low birth weight premature infants with visceroabdominal disproportion(VAD).

Methods: 57 infants with VAD (32 patient gastroschisis, 25 patient - omphalocele) weighing 501 to $1000 \mathrm{~g}$, less than 4 hours of age and required ventilation with airway pressure $>4-6 \mathrm{~cm}$ $\mathrm{H}_{2} \mathrm{O}$ and $\mathrm{FiO}_{2}>0.25$, and had an anticipated duration of ventilation greater than 48 hours. Newborn were stratified by birth weight and prenatal steroid status, and then randomized to either HFOV or SIMV with tidal volume monitoring.

Results: Data are presented for 37 HFOV and 20 SIMV infants (two infants, twins, were withdrawn from the study at parent's request). 36 of the 37 HFOV infants and 17 of the 20 SIMV infants survived to 36 weeks corrected age. Age at final extubation for survivors was 6,02 $\pm 2,03$ (mean \pm SD) days for HFOV infants and $10,41 \pm 4,10$ days for SIMV infants. At 36 weeks corrected age, 36 of the $37 \mathrm{HFOV}$ survivors were extubated and in room air, whereas 4 required supplemental oxygen. In comparison, 17 of the 20 SIMV survivors were extubated and in room air, whereas 9 required supplemental oxygen. Grade III/IVIVH and/or periventricular leukomalacia occurred in $1 \mathrm{HFOV}$ and 8 SIMV patients.

Conclusions: The protocols for the Early HFOV vs. SIMV in VLBW Infants ventilator management of VLBW infants, both with HFOV and with SIMV were easily implemented and consistently followed, and are presented here.

\section{8}

\section{ETILOGY OF ACUTE DIARRHEA IN CHILDREN IN A SECONDARY CARE HOSPITAL}

\section{S.F. Paupério, A. Leitão, J.G. Dinis, A. Sousa \\ Centro Hospitalar do Médio Ave - Unidade de Santo Tirso, Santo Tirso, Portugal}

Background and aims: Diarrhea refers to the passage of loose or watery stools, and occurs at some point in the life of nearly every child. Diarrhea can lead to dehydration, which alters the child's natural balance of water and electrolytes and can be serious if not treated promptly.

Several factors can contribute to intestinal infections: duration of maternal breast feeding, food and enviromental contaminations, maternal education, home location, family income, access to treated water and basic sanitary conditions, seasonal variations and in special, the age of the host. Rotavirus is the most important etiologic agent of acute diarrhea in infants and young children.

The aims of this study are: determine prevalence of acute diarrhea (AD) in children admitted to our hospital between January 2008 and December 2009 and determine etiologic viral agents of AD.

Materials and methods: Retrospective study of patients aged 0-16 years admitted between January 2008 and December 2009. Stool specimens were analyzed by enzyme-linked immuno sorbent assay (ELISA) for viral agents (Rotavirus and Adenovirus).

Results: We studied 114 patients during 2 years. Rotavirus was detected in 56 cases. Adenovirus 
was detected in 4 cases. The mean age was 10 months. The $A D$ was more frequent during winter months. The prevalence of $A D$ was equivalent in both genders. The mean hospital stay was shorter in the last year.

Conclusion: Acute diarrhea is an important cause of admission in our departament and Rotavirus is an important etiological agent of acute diarrhea in children. Preventive strategies must be implemented in our community.

\section{9}

\section{CORELATION OF GROWTH HORMONE ANALYSIS WITH LINEAR GROWTH IN EXTRAHEPATIC PORTAL VENOUS OBSTRUCTION IN CHILDREN}

\author{
G.S. Sidhu, P. Rawal, B. Thapa, C.K. Nain, \\ K.K. Prasad, B. Nagi, K. Singh \\ PGIMER Chandigarh, Chandigarh, India
}

Introduction: EHPVO has been considered to cause short stature. But, information about growth hormone analysis in extrahepatic portal venous obstruction (EHPVO) in children is limited. We therefore studied these parameters in EHPVO children $(<18$ years of age).

Methods: The diagnosis of extrahepatic portal venous obstruction (EHPVO) was made on the basis of ultrasound examination. This Prospective study conducted over 52 children of EHPVO with 41 patients in group 1 (normal stature) and 11 patients in group 2(short stature) as per NCHS standards. Levels of GH and IGF1 of all patients $(n=52)$ were compared to normal healthy children $(n=20)$. Levels of normal stature group were also compared to short stature group.

Results: Levels of growth hormone was significantly higher in patient population $(67.37 \pm 25.66 \mathrm{ng} / \mathrm{ml})$ as compared to controls $(4.66 \pm 2.74 \mathrm{ng} / \mathrm{ml})$, while IGF 1 was significantly lower in patient population $(3.85 \pm 4.17 \mathrm{ng} / \mathrm{ml})$

as comparison to control population $(91.30 \pm 60.88$ $\mathrm{ng} / \mathrm{ml})$. But, there was no difference of growth hormone and IGF 1 levels between group1 and group 2.

Conclusion: It is noteworthy here that growth hormone resistance exists in EHPVO. As there was no difference between normal stature and short stature, so, it does not seem to effect on growth. Further studies required to confirm this observation.

760

\section{RADIONUCLIDE GASTROESOPHAGEAL REFLUX SCAN; AN EFFECTIVE SCREENING TOOL FOR INFANTS/CHILDREN WITH REPEATED CHEST INFECTIONS}

\author{
O.Q. Gill \\ Nuclear Medicine, PINUM Hospital, \\ Faisalabad, Pakistan
}

Objective: Unexplained recurrent chest infections are a cause of failure to thrive in infants and young children. Repeated hospital admissions with respiratory symptoms are an extra economic burden on the health budget along with the morbidity. Aim of this study was twofold; first to analyze the utility of Nuclear Medicine to screen children with clinically significant gastroesophageal reflux and secondly to evaluate the lesion after conventional treatment.

Place of study: Punjab Institute of Nuclear Medicine in collaboration with department of pediatrics, Allied Hospital Faisalabad.

Patients and methods: Seventy clinically symptomatic patients underwent Gastroesophageal Reflux (GER) Scan with effective fasting of 1-3hrs. $20-37 \mathrm{MBq}$ of ${ }^{99 \mathrm{~m}} \mathrm{Tc}$ labeled Colloid was diluted in milk for oral intake. 30min dynamic study with 3 second per frame was acquired. Both qualitative and quantitative analysis was done using cine review, time active curves (TAC) and percentage reflux index $(\% \mathrm{RI})$. Patients with high grades of reflux were reviewed again after 08 weeks of conventional antireflux treatment.

Results: $63 \%$ of the patients (44/70) were reflux positive, of which (26/44) were in grade I/II category while (13/44) showed moderate degree reflux and only (2/44) showed severe reflux. Chest infection was the chief clinical presentation in each case $(57 \%)$. Eighty percent of selected patients (8/10) showed improvement with conventional antireflux treatment.

Conclusion: GER scan is a non-invasive, effective way of screening clinically symptomatic babies for reflux of gastric contents. Quantitative assessment of improvement after conventional antireflux treatment offers cost-effective follow-up of GERD. 